\title{
EEG as a Predictor of Poorly- Controlled Childhood Epilepsy
}

\author{
Mohammad Asaduzzaman ${ }^{* 1}$, Md. Mizanur Rahman²
}

\section{Abstract}

Introduction:The aim of the present study was to determine electroencephalographic factors associated with poorly controlled epilepsy. Materials and Methods: This retrospective study was performed from January 2007 to December 2008 at Paediatric Neurology outpatient department in Bangabandhu Sheikh Mujib Medical University, Dhaka, among the children with epilepsy of 7 months to 15 years age who had history of at least 6 months treatment with rational antiepileptic drugs daily with adequate compliance. There were two groups of patients; group 1, consisted of 50 poorly controlled epilepsy patients and group 2, comprised 50 well-controlled epilepsy patients. We retrospectively reviewed EEGs and medical records from these children. Features of initial EEGs findings were compared between the two groups. Results: Significant electroencephalographic predictors of poorly controlled epilepsy were: abnormal initial EEG $(p=0.025)$, EEG background abnormality $(p<0.001)$, frequent sharp wave/spike $(p<0.001)$ and hypsarrhythmia $(p=0.046)$. No significant difference was noticed between the two groups in respect to the location of spikes/ sharp waves. With multiple logistic regression, independent predictors of poor seizure control were EEG background abnormality and frequent sharp wave/spike. Conclusion: The study showed several Electroencehalographic factors that can be identified early in the course of childhood epilepsy which can predict development of poor seizure control. Knowledge of these factors will help us to discriminate our patients and pay more attention to those at risk of developing poorly controlled epilepsy.

Keywords: Electroencephalogram (EEG), Poorly controlled epilepsy.

Number of Tables: 06; Number of Figure: 01; Number of References: 21; Number of Correspondence: 05.

*1. Corresponding Author:

\section{Dr. Mohammad Asaduzzaman}

MD (Paediatrics)

Junior Consultant, Department of Paediatrics

Sherpur District Hospital.

Email: drmdzaman1973@gmail.com

Mobile: +8801712000511

2. Professor Dr. Md. Mizanur Rahman

Professor and Chairman

Department of Paediatric Neurology

Bangabandhu Sheikh Mujib Medical University, Dhaka.

\section{Introduction:}

Seizures are common in the paediatric age group and occur in approximately $10 \%$ of the children ${ }^{1}$. The largest number of newly diagnosed patients with epilepsy occurs between birth and 2 years of age $^{2}$. Epilepsy is considered to be present when two or more unprovoked seizures occur at an interval greater than 24 hours apart ${ }^{1}$. One or more seizures per month over a period of 6 months or more even after experiencing trials of at least two different antiepileptic drugs alone or in combination at optimum doses with adequate compliance is called intractable epilepsy ${ }^{3}$. Epilepsy is refractory when seizures are so frequent or severe that they limit the patient's ability to live life fully according to his or her wishes or necessitate the use of medications that, although effective, produce adverse effects ${ }^{4}$.
Fortunately, most children with epilepsy do well when treated with an antiepileptic drug 5 . Numerous studies have reported predictors of favorable outcome of epileptic seizures in children and adults. Most report that $70-80 \%$ of patients eventually become seizure free $e^{6}$. But $10-20 \%$ of children with epilepsy have persistent seizures refractory to drugs, and those cases pose a diagnostic and management challenge ${ }^{1}$. However, what becomes of the group of children who continue to have seizures despite adequate trials of drugs? Although this is a small group of children, the medical, social, and economic consequences of poorly controlled seizures can be enormous. These children are at high risk for behavioral and academic difficulties ${ }^{7}$. In addition to the often catastrophic effects of uncontrolled seizures on the child, the burden on the parents of dealing with the multitude of daily problems accompanying intractable epilepsy cannot be underestimated ${ }^{2}$.

Most studies regarding poor seizure control are concentrated towards the clinical predictors. Very little is known about the childhood epilepsies in Bangladesh ${ }^{8}$. Factors most predictive of poor seizure remission were: multiple types of seizures, poor cognition at presentation, high rates of seizures, associated motor disability and EEG abnormalities ${ }^{8}$.

One Indian study showed that EEG was abnormal in $69 \%$ cases with background abnormality being present in $20 \%$ of intractable epilepsy 9 . Another study from Iran showed that the 1st EEG was abnormal more in patients of intractable epilepsy than those of well controlled epilepsy ${ }^{10}$. The outcome of seizure is poorer if EEG shows background abnormality and focal epileptiform activity ${ }^{11}$. In general patients with anterior temporal and frontal focus tend to have lower remission rate than those with mid temporal focus ${ }^{11}$. But another study did not notice any significant difference in severity of epilepsy 
with frontal and temporal focus ${ }^{9}$. Focal EEG slowing was associated with an increased risk of intractableepilepsy ${ }^{12}$. Children with intractable epilepsy were more likely to have abnormal EEG background, frequent discharges $(>1 / 60$ s) and focal spike and waves than those with well controlled epilepsy ${ }^{13}$. Generalized epileptiform activity, whether early or well along in the course of new cases of epilepsy, is associated with a lower chance of remission ${ }^{14}$.

As literatures were reviewed there were no published data about this type of study in our country. This study is intended to provide electroencephalographic information regarding poorly controlled epilepsy that may guide the physician for early identification of these patients for counseling their families, selecting patients for intensive investigations and treatment, as well as early consideration of epilepsy surgery to prevent consequences of poorly controlled epilepsy on quality of life.

\section{Materials and Methods:}

This case-control study was conducted from January 2007 to December 2008 at Paediatric Neurology OPD, Bangabandhu Sheikh Mujib Medical University. 50 cases of intractable epilepsy in group-1 and 50 cases of well-controlled epilepsy in group- 2 were enrolled in the study. Children of either sex with epilepsy, aged 7 months to 15 years with history of at least one unprovoked seizure per month for 6 or more months and history of treatment with 2 or more rational antiepileptic drugs (AED) daily, either singly or in combination for at least 6 months and adequate compliance to antiepileptic drugs were considered as case. Children of either sex with epilepsy, aged 7 months to 15 years who had been seizure-free during 6 months after start of treatment were considered as control. Poorly controlled epilepsy was defined as one or more seizure per month over a period of 6 months or more even after experiencing trials of at least two different antiepileptic drugs alone or in combination at optimum doses with adequate compliance. Well-controlled epilepsy was defined as no seizure during 6 months after start of treatment with AED.

Once the child was reporting, a structured questionnaire was completed, containing pre-defined variables of clinical and EEG information that may help predicting the intractability. Then a detailed history including gender, age of onset, number of seizures before starting the treatment, type of epilepsy, character of seizure, status epilepticus, initial seizure frequency, history of neonatal seizures, family history of epilepsy, history of complex febrile seizure, treatment history, etc. were recorded and medical records were reviewed. Details regarding antiepileptic drugs were recorded i.e. number of drugs, duration of therapy, dosage and compliance. It was noted whether the choice of drugs were correct or incorrect in relation to seizure type and the dosage schedule was proper according to body weight. Thorough physical examination including neurodevelopmental and psychological assessment was done. All study patients were seen by a consultant Paediatric Neurologist of the unit. Seizures were classified using the International League Against Epilepsy (ILAE) classification of epileptic seizure. Interictal EEG recordings obtained with a 19 channel Electroencephalograph, employing scalp electrodes placed according to the international 10-20 system were studied. Patients who had EEGs done from the same institute were only considered and EEGs were interpreted by 2 Pediatric Neurologists expert in EEG interpretation. Although many of the children had multiple EEGs, information obtained from the first EEG was used. EEG findings were grouped into two main categories: 'normal' for the age and state of the child and 'abnormal'. Abnormal EEG was defined as the presence of interictal epileptiform discharges and/or the presence of background abnormal activity. Specific epileptiform abnormalities likefocal spikes, multifocal spikes, generalized spikes and waves, frequent sharp wave/ spike, hypsarrhythmia as well as background abnormalities were coded separately. Serum drug level was not measured. An antiepileptic drug was considered to have failed if it did not control seizures in spite of good compliance or if medication was discontinued because of unacceptable side effects. A drug used acutely to treat status epilepticus was not counted as one of the two AEDs. Child was a case or a control. Group1 consisted of poorly controlled epilepsy patients and Group2 comprised well-controlled epilepsy patients. A comparison of various EEG and clinical factors between the two groups was done. Data were analyzed using statistical package SPSS (version 15.0). Standard tests of significance, such as Chi-square test was applied for categorical variables and't' test was done for quantitative variables. The Odds ratio (OR) was used as estimation of risk to indicate the magnitude of association between each factor and poorly-controlled epilepsy. 95\% confidence interval (CI) and $\mathrm{p}$ values were also computed. P-value of $<0.05$ was considered significant. Multivariate analysis was performed to choose independently significant factors among the many significant factors in bivariate analysis.

\section{Results:}

Table I shows that $54 \%$ of the poorly-controlled epilepsy patients and $44 \%$ of well controlled epilepsy patients were between 1-5 years age group. However there was wide spread distribution in different age groups. The mean age was found to be $4.59 \pm 3.19$ years in poorly-controlled group and $5.91 \pm 3.72$ years in well- controlled group. No significant statistical difference was observed between poorly-controlled and well-controlled group in respect to age $(p=0.062)$. In poorly-controlled group $60.0 \%$ were males and $40.0 \%$ were females, while in well-controlled group males and females were $66.0 \%$ and $34.0 \%$ respectively. There was no significant statistical difference between the two groups in respect to $\operatorname{sex}(p=0.534)$. 
Table-I: Distribution of the subjects by demographic variables $(n=100)$.

\begin{tabular}{|c|c|c|c|c|}
\hline \multirow{2}{*}{\multicolumn{2}{|c|}{ Variables }} & \multicolumn{2}{|c|}{ Groups } & \multirow[t]{2}{*}{ p value } \\
\hline & & $\begin{array}{c}\text { Group1 }(n=50) \\
\text { No }(\%)\end{array}$ & $\begin{array}{c}\text { Group2 }(n=50) \\
\text { No }(\%)\end{array}$ & \\
\hline \multicolumn{5}{|c|}{ Age (year) } \\
\hline$\circ$ & $\leq 1$ year & $5(10.0)$ & $1(2.0)$ & \\
\hline O & $1-5$ years & $27(54.0)$ & $22(44.0)$ & \\
\hline ० & $5-10$ years & $16(32.0)$ & $20(40.0)$ & \\
\hline & $>10$ years & $2(4.0)$ & $7(14.0)$ & \\
\hline \multicolumn{2}{|c|}{ Mean \pm SD } & $4.59 \pm 3.19$ & $5.91 \pm 3.72$ & \\
\hline \multicolumn{2}{|c|}{ Sex } & & & $0.062^{\mathrm{NS}(\mathrm{a})}$ \\
\hline o & Female & $20(40.0)$ & $17(34.0)$ & \\
\hline ○ & Male & $30(60.0)$ & $33(66.0)$ & $0.534^{\mathrm{NS}(\mathrm{b})}$ \\
\hline
\end{tabular}

aUnpaired $t$ test was done to measure the level of significance. bChi-square test was done to measure the level of significance.

Table II shows that $96.0 \%$ of the patients in poorly-controlled epilepsy group had abnormal EEG in contrast to $82.0 \%$ of the patients in well-controlled epilepsy group $(\mathrm{p}<0.05)$

Table II: Distribution of the subjects by initial EEG status $(\mathrm{n}=100)$.

\begin{tabular}{|lllll|}
\hline EEG & \multicolumn{2}{c}{ Groups } & OR (CI) & p value \\
\cline { 2 - 3 } & $\begin{array}{l}\text { Group1(n=50) } \\
\text { No (\%) }\end{array}$ & $\begin{array}{l}\text { Group2(n=50) } \\
\text { No (\%) }\end{array}$ & & \\
\hline Normal & $2(4.0)$ & $9(18.0)$ & $5.27(1.08-25.78)$ & $0.025^{*}$ \\
Abnormal & $48(96.0)$ & $41(82.0)$ & & \\
\hline
\end{tabular}

Chi-square test was done to measure the level of significance. ${ }^{*} \mathrm{p}<0.05$

This figure shows that in poorly controlled group location of spikes/ sharp waves was predominantly generalized $(38.0 \%)$ followed by multifocal $(20 \%)$ and focal $(20 \%)$, focal with secondary generalization being least common $(6.0 \%)$. On the other hand in well-controlled group location of spikes/ sharp waves is predominantly focal $(32.0 \%)$ followed by generalized $(22.0 \%)$, multifocal $(12 \%)$ and focal with secondary generalization $(4.0 \%)$. But no significant statistical difference was noticed between the two groups in respect to location of spikes/sharp waves $(\mathrm{b}>0.05)$.

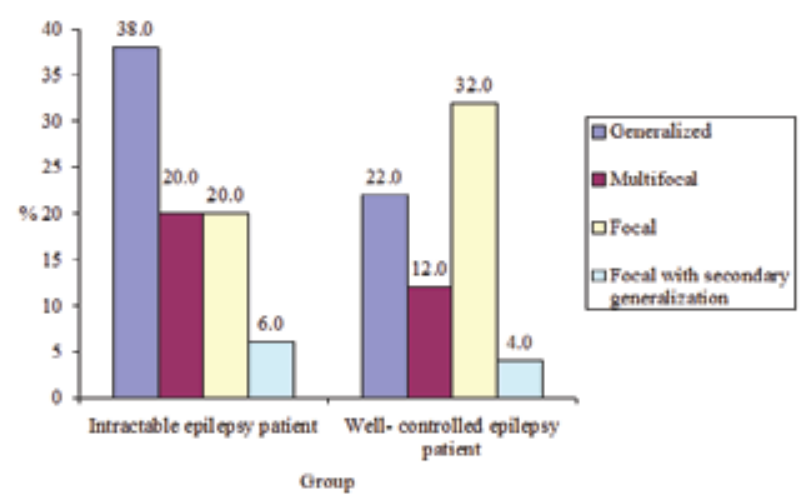

Figure-1: Multiple bar diagram showing location of spikes/sharp waves of EEG in two groups ( $\mathrm{n}=100)$.
Table III demonstrates $64.0 \%$ of the patients in poorly-controlled group had frequent sharp waves/ spikes $(>1 / 60 \mathrm{sec})$ compared to $24.0 \%$ in well-controlled group $(\mathrm{p}<0.001)$. Analysis also shows that hypsarrhythmia was found to be present in $16.0 \%$ of the patients in poorly-controlled group as compared to only $4.0 \%$ of the patients in well-controlled $\operatorname{group}(\mathrm{p}<0.05)$.

Table-III: Distribution of the subjects by frequent sharp wave /spike (>1/60 sec) and hypsarrhythmia $(n=100)$.

\begin{tabular}{lllll}
\hline Variables & \multicolumn{2}{c}{ Groups } & OR (CI) & p value \\
\cline { 2 - 3 } & $\begin{array}{l}\text { Group1 } \\
(\mathbf{n}=\mathbf{5 0})\end{array}$ & $\begin{array}{l}\text { Group2 } \\
\mathbf{( n = 5 0 )}\end{array}$ & & \\
& $\mathbf{N o}(\%)$ & No (\%) & & \\
\hline Frequent sharp wave/spike & $32(64.0)$ & $12(24.0)$ & $5.63(2.38-13.32)$ & $<0.001^{* *}$ \\
Hypsarrhythmia & $8(16.0)$ & $2(4.0)$ & $4.57(1.03-19.98)$ & $0.046^{*}$ \\
\hline
\end{tabular}

Chi-square test was done to measure the level of significance.

Table IV demonstrates that no significant difference was noticed between the two groups in the development of poor seizure control in respect to the location of focal spikes/waves $(p>0.05)$. In case of multifocal spikes/waves involvement of fronto-temporal $(8.0 \%)$ and tempo-parietal lobes $(6.0 \%)$ were more in poorly-controlled group in comparison to well-controlled group in which case involvement of these lobes were only $2 \%$ respectively. But no significant difference was noticed between the two groups in the development of poor seizure control in respect to the location of multifocal spikes/waves ( $p>0.05)$.

Table-IV: Distribution of the subjects by location of the spike/sharp wave in different lobe/lobes of cerebral hemispheres $(\mathrm{n}=100)$.

\begin{tabular}{|c|c|c|c|c|c|}
\hline \multirow{2}{*}{\multicolumn{2}{|c|}{$\begin{array}{l}\text { Location of spike/sharp } \\
\text { wave in lobe/lobes of } \\
\text { cerebral hemispheres }\end{array}$}} & \multicolumn{2}{|c|}{ Groups } & \multirow[b]{2}{*}{ OR (CI) } & \multirow[b]{2}{*}{ p value } \\
\hline & & $\begin{array}{l}\text { Group1 } \\
(n=50)\end{array}$ & $\begin{array}{l}\text { Group2 } \\
(\mathrm{n}=50)\end{array}$ & & \\
\hline \multicolumn{6}{|l|}{ If focal } \\
\hline$\circ$ & Frontal & $6(12.0)$ & $2(4.0)$ & $\begin{array}{c}3.27 \\
(0.71-14.86)\end{array}$ & $0.269^{\mathrm{NS}}$ \\
\hline ○ & Temporal & $2(4.0)$ & $5(10.0)$ & $\begin{array}{c}0.38 \\
(0.08-1.78)\end{array}$ & $0.436^{\mathrm{NS}}$ \\
\hline$\circ$ & Parietal & $1(2.0)$ & $2(4.0)$ & $\begin{array}{c}0.49 \\
(0.06-3.89)\end{array}$ & $0.999^{\mathrm{NS}}$ \\
\hline$\circ$ & Occipital & $0(0.0)$ & $4(8.0)$ & & $0.117^{\mathrm{NS}}$ \\
\hline ○ & Central & $3(6.0)$ & $3(6.0)$ & & $0.999^{\mathrm{NS}}$ \\
\hline \multicolumn{6}{|c|}{ If multifocal } \\
\hline$\circ$ & Fronto-temporal & $4(8.0)$ & $1(2.0)$ & $\begin{array}{c}4.26 \\
(0.61-29.18)\end{array}$ & $0.362^{\mathrm{NS}}$ \\
\hline$\circ$ & Temporo-parietal & $3(6.0)$ & $1(2.0)$ & $\begin{array}{c}3.13 \\
(0.43-22.46)\end{array}$ & $0.617^{\mathrm{NS}}$ \\
\hline$\circ$ & Centrotemporal & $1(2.0)$ & $4(8.0)$ & $\begin{array}{c}0.234 \\
(0.03-1.64)\end{array}$ & $0.362^{\mathrm{NS}}$ \\
\hline
\end{tabular}

Fisher Exact test was done to measure the level of significance.

Table $\mathrm{V}$ demonstrates that $78 \%$ of the patients in Poorly-controlled group had background EEG abnormality compared to $30 \%$ of the patients in well-controlled group $(p<0.001)$. Diffuse background slowing was present in $18.0 \%$ of the patients of poorly-controlled epilepsy compared to $4.0 \%$ in well-controlled patients $(p=0.025)$. Focal slowing was present in $16.0 \%$ cases of well-controlled group compared to $8.0 \%$ in poorly controlled group. But no significant difference was noticed between the two groups. 
Table-V: Distribution of the subjects by EEG background findings $(n=100)$.

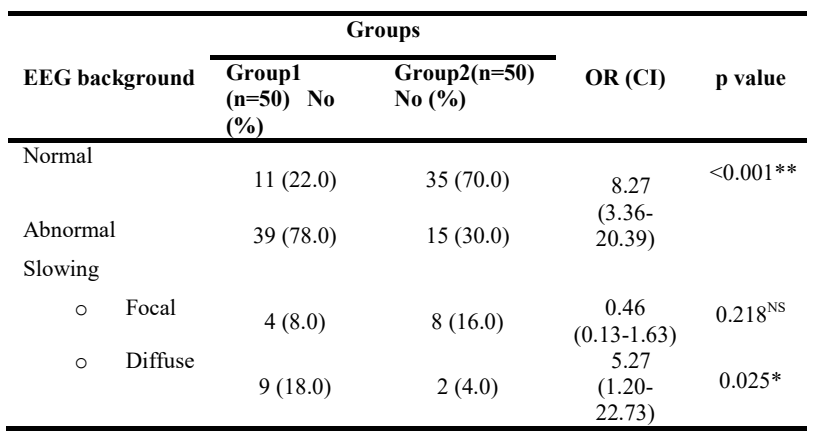

Chi-square test was done to measure the level of significance. ${ }^{*} \mathrm{p}<0.05$

Table VI demonstrates logistic regression analysis for the EEG predictors of poorly-controlled epilepsy. Out of the 3 variables, abnormal EEG background $(\mathrm{OR}=11.12$; $95 \%$ $\mathrm{CI}=3.66-33.74)$ and frequent sharp wave/ spike $(\mathrm{OR}=8.06$; $95 \% \mathrm{CI}=2.67-24.31$ ) were found to be the independent predictors of poorly-controlled epilepsy.

Table-VI: Logistic regression analysis for electroencephalographic predictors of Poorly-controlled childhood epilepsy.

\begin{tabular}{|c|c|c|c|}
\hline \multirow[t]{2}{*}{ Predictors } & Model I & Model II & Model III \\
\hline & Unadj. OR (CI) & $\overline{A d j . ~ O R ~(C I) ~}$ & Adj. OR (CI) \\
\hline Abnormal EEG background & $\begin{array}{l}8.27^{*} \\
(3.36-20.39)\end{array}$ & $\begin{array}{l}11.62^{*} \\
(3.90-34.58)\end{array}$ & $\begin{array}{l}11.12 * \\
(3.66-33.74)\end{array}$ \\
\hline Frequent sharp wave/ spike & & $\begin{array}{l}8.29 * \\
(2.77-24.80)\end{array}$ & $\begin{array}{l}8.06^{*} \\
(2.67-24.31)\end{array}$ \\
\hline Hypsarrhythmia & & & $\begin{array}{l}1.42 \\
(0.24-8.60)\end{array}$ \\
\hline
\end{tabular}

\section{Discussion:}

This study was done to search the elctroencephalographic factors that are associated with the poor control of childhood epilepsy. While there had been a number of recent studies designed to evaluate predictors of medical intractability in children, most have concentrated on clinical factors. This retrospective study demonstrated that there were a number of electroencephalographic factors that were associated with poor seizure control. Early identification of these factors might help in planning early intervention.

Table I illustrates the demographic characteristics of the patients. Age (mean \pm SD) at presentation of poorly controlled group was $4.59 \pm 3.19$ years and that of well-controlled group was $5.91 \pm 3.72$ years. No significant statistical difference was observed between poorly controlled and well-controlled group in respect to age $(\mathrm{p}=0.534)$. In poorly controlled group males were $(60.0 \%)$ and females were $(40.0 \%)$ and in well-controlled group males and females were $66.0 \%$ and $34.0 \%$ respectively. In both groups males were predominant. No significant statistical difference was observed in this study in respect to sex between poorly controlled and well-controlled group $(p=0.062)$ that is poor seizure control occurs with equal frequency in both sexes.
This finding was supported by the study done by Kwan $\mathrm{P}$ et al. ${ }^{15}$ who did not find any significant difference in sex between the groups that become seizure free and the group with uncontrolled seizure. They found that $52 \%$ of the patients with uncontrolled epilepsy were male and $47 \%$ were female, whereas $47 \%$ male and $53 \%$ female were found in patients who were seizure free. But Malik et al. ${ }^{16}$ found that male gender was a risk factor for intractable seizures $(p=0.001)$ and this finding was similar to that previously done by Akhondian et al. ${ }^{10}$ The male predominance in this study was more likely to be because of a selection bias.

Table II shows that $96.0 \%$ of the patients in poorly controlled group have abnormal EEG in contrast to $82.0 \%$ of patients in well-controlled group. EEG abnormality was significantly associated with poor seizure control of childhood epilepsy $(p=0.025)$. This finding was similar to those done by many authors.Singhviet al. ${ }^{9}$ found that EEG was abnormal more in poorly controlled epilepsy patients (69\% cases). Banuet $a .^{8}$ found that EEG was abnormal in $80.8 \%$ cases and it was found to be associated with more than 4 times $(\mathrm{OR}=4.09)$ risk to poor seizure remission $(p=0.0016)$. Similar finding was seen by Akhondianet al. ${ }^{10}$ who found that the first EEG was abnormal in $96.1 \%$ of patients in the poorly controlled epilepsy group and in $83.8 \%$ of the patients in the well-controlled group $(p=0.031)$. Das et al. ${ }^{17}$ found that an abnormal EEG was a significant factor for recurrence $(75 \%$ versus $16 \%$ in cases with normal EEG). Another study carried out by Malik et al. ${ }^{16}$ found that higher proportion of the patients with abnormal EEG continued to have seizures during the study period compared to patients with normal EEG $(63 \%$ vs. $19 \%$; $\mathrm{OR}=7.28 ; 95 \% \mathrm{CI}=4.34-12.18$; $\mathrm{p}$-value $<0.001)$.

The figure in this study shows that generalized location of spikes/ sharp waves is higher in poorly controlled group (38.0\%) compared to well-controlled group (22.0\%). In well- controlled group focal spikes/ sharp waves was found to be higher $(32.0 \%)$. This finding was supported by the study done by Shafer et al. ${ }^{14}$ who found that the absence of generalized epileptiform activity was associated with epilepsy remission, defined as 5 years without any seizure. The authors also found that focal epileptiform activity on the first EEG was associated with a good prognosis, perhaps reflecting a high percentage of patients with benign Rolandic epilepsy. But the findings by Ko and Holmes $^{13}$ shows that focal spikes and wave discharges were more common in the medically intractable group. Study by Singhviet al. ${ }^{9}$ also noticed that focal epileptiform discharges were commoner $(36 \%)$ than generalized discharges $(21 \%)$. In this study multifocal spikes/ sharp waves were more common in poorly controlled epilepsy group than well controlled group (20\% vs. 12\%). But it was not statistically significant $(\mathrm{p}>0.05)$. This is similar to the finding by Ko and Holmes ${ }^{13}$ who found that children with poorly controlled epilepsy group were more likely to have multifocal sharp waves and spikes than those with well controlled seizures $(45.8 \%$ vs. $30.8 \%)$ but failed to show statistical significance. 
This study showed that in case of focal spikes/waves, frontal lobe involvement was higher $(12.0 \%)$ in poorly controlled group compared to well-controlled group $(4.0 \%)$ (Table IV). Okuma \& Kumashiro ${ }^{11}$ also found that patients with anterior temporal or frontal focus tended to show lower remission rate of seizure than those with other topography of paroxysmal activity $(p=<0.01)$. In case of multifocal spikes/waves we found that involvement of fronto-temporal $(8.0 \%)$ and tempo-parietal lobes $(6.0 \%)$ were more in poorly controlled group. This was similar to the finding by Singhviet al. ${ }^{9}$ who found that frontotemporal lobe involvement was in $10 \%$ cases followed by temporal $(8 \%)$ and frontal $(6 \%)$ lobe. Ohtsukaet al. ${ }^{18}$ also described that the rate of poorly controlled epilepsy patients was high in frontal lobe epilepsy and multi lobar epilepsy.

Frequent sharp wave /spike ( $>1 / 60 \mathrm{sec})$ was found to be a significant predictor for poorly controlled epilepsy (table III). In multivariate analysis it was found to be an independent predictor of poor seizure control (Table VI). Ko and Holmes ${ }^{13}$ found that $52.1 \%$ of children with poorly controlled epilepsy had frequent sharp wave /spike $(>1 / 60 \mathrm{~s})$ compared to $23.1 \%$ of children with well-controlled epilepsy $(\mathrm{p}<0.01)$. Hypsarrhythmia was found to be significantly associated with poor seizure control $(p=0.046)$ but it was no longer significant in multivariate analysis (Table VI). Boyd \&Harden ${ }^{21}$ described that hypsarrhythmia may develop as a result of an early cerebral insult, whether focal or multifocal, such as infarction, porencephalic cysts, microangiopathy or in infants with developmental anomalies. They also described that whatever the clinical picture, the presence of hypsarrhythmia was an indicator of poor prognosis.

Among the EEG abnormalities EEG background abnormality was the most common abnormality noticed in the poorly controlled group $(78.0 \%)$ (Table V). It was significantly associated with poorly controlled epilepsy $(p=0.001)$. In multivariate analysis EEG background abnormality was found to be an independent predictor of poor seizure control (Table VI). This finding was supported by several studies. Ko and Holmes ${ }^{13}$ found that abnormal EEG background was present in $73.6 \%$ cases in poorly controlled epilepsy group. Banuet al. ${ }^{8}$ found that abnormal background activity was present in $34.4 \%$ cases and was associated with poor seizure remission. Study done by Okuma \& Kumashiro ${ }^{11}$ also showed that the remission rate was lowest in patients with severely and diffusely abnormal EEG background activity $(p<0.001)$. Study carried out by Laroiaet al. ${ }^{19}$ showed that EEG background abnormalities strongly predicted the occurrence of electrographic seizures in neonates concomittently or in the subsequent 18-24 hrs of recording. Among background abnormalities this study found that diffuse slowing was associated with increased risk for poor seizure control $(p=0.025)$. Ko and Holmes ${ }^{13}$ showed that diffuse slowing was the most significant factor for poorly controlled epilepsy $(p=0.01)$. But Berg et al. ${ }^{12}$ showed that focal EEG slowing $(p=0.02)$ was an independent predictor of poorly controlled epilepsy. Shinnaret $\mathrm{al}^{20}$ also found that focal slowing was associated with a high risk of recurrence. In the present study, underlying causes were not studied or correlated with the EEG changes.

After multiple logistic regression of significant electroencephalographic factors in bivariate analysis, we found that EEG background abnormality and frequent sharp wave/ spike were significant independent predictors of poorly controlled epilepsy (Table VI).

\section{Conclusion:}

This study shows that there are a number of electroencephalographic factors that can be identified early in the course of childhood epilepsy that are predictive of poor seizure contro. Knowledge of these factors will help us to discriminate our patients and pay more attention to those at risk of developing poorly controlled seizures.

\section{Conflict of Interest: None.}

\section{Acknowledgement:}

Thanks and all praise to Almighty Allah, the beneficent, the merciful for providing us enough energy and patience to complete this article. Our special thanks and gratitude to Prof (Dr) C.A. Kawser, Professor and Ex chairman, Department of General Paediatrics, Bangabandhu Sheikh Mujib Medical University, Dhaka, Bangladesh for providing instructions, encouragement and valuable advice from beginning of this study. We would like to express our sincere gratitude and gratefulness to all teachers, doctors and employee in the department of paediatrics, Bangabandhu Sheikh Mujib Medical University, Dhaka, Bangladesh for valuable suggestions and advices to complete this study.

\section{References:}

1. Johnston MV. Seizures in childhood. In: Behrman RE, Kleigman RM and Jenson HB, editors. Nelson Text book of Paediatrics. 17th ed. Philadelphia: Saunders; 2004:1993-2009.

2. Holmes GL, Engel J Jr. Predicting medical intractability of epilepsy in children. How certain can we be? Neurology. 2001; 56:1430-1431.

https://doi.org/10.1212/WNL.56.11.1430

\section{PMid:11402096}

3. Chawla S, Aneja S, Kashyap R, Mallika V. Etiology and clinical predictors of intractable epilepsy .Pediatr Neurol. 2002; 27( 3): 186-191.

https://doi.org/10.1016/S0887-8994(02)00416-2

4. Devinsky O. Patients with refractory seizures. The new England journal of Medicine.1999; 340(20): 1565-1570.

https://doi.org/10.1056/NEJM199905203402008

PMid:10332020

5. Camfield PR, Camfield CS, Gordon K, Dooley JM. If a first antiepileptic drug fails to control a childhood epilepsy what are the chances of success with the next drug? J Pediatr. 1997; 131: 821-824. 
https://doi.org/10.1016/S0022-3476(97)70027-1

6. Annegers JP, Hausen WA, Elveback LR. Remission of Seizures and Relapse in patients with Epilepsy', Epilepsia. 1979; 20: 729-737.

https://doi.org/10.1111/j.1528-1157.1979.tb04857.x

PMid:499118

7. Holmes GL. Epilepsy in the developing brain: lessons from the la boratory and clinic. Epilepsia. 1997; 38: 12-30. https://doi.org/10.1111/j.1528-1157.1997.tb01074.x

PMid:9024181

8. Banu SH, Khan NZ, Jahan A, Parveen M, Rahman N, Boyd SH, et al. Profile of childhood epilepsy in Bangladesh. Developmental Medicine and Child Neurology. 2003; 45: 477-482.

https://doi.org/10.1017/S0012162203000884

https://doi.org/10.1111/j.1469-8749.2003.tb00943.x

PMid: 12828402

9. Singhvi JP, Sawhney IM, Lal V, Pathak A, Prabhakar, S. Profile of intractable epilepsy in a tertiary referral centre. Neurol India. 2000; 48(4): 351-356.

10. Akhondian J, Heydarian F, Jafari, SA. Predictive factors of pediatric intractable seizure. Arch Iranian Med. 2006; 9(3): 236-239.

11. Okuma T, Kumashiro H. Natural history and prognosis of epilepsy: Report of a multi-institutional study in Japan. Epilepsia. 1981; 22: 35-53.

https://doi.org/10.1111/j.1528-1157.1981.tb04331.x

PMid:7472299

12. Berg AT, Shinnar S, Levy SR, Testa FM, Smith-Rapaport S, Beckerman B. Early development of intractable epilepsy in children: a prospective study. Neurology. 2001; 56: 1445-1452.

https://doi.org/10.1212/WNL.56.11.1445

PMid:11402099
13. Ko TS, Holmes GL. EEG and clinical predictors of medically intractable childhood epilepsy. Clinical

Neurophysiology.1999; 110: 1245-1251.

https://doi.org/10.1016/S1388-2457(99)00068-1

14. Shafer SQ, Hauser WA, Anneger JF, Klass DW. EEG and other early predictors of epilepsy remission: a community study. Epilepsia. 1988; 29(5): 590-600.

https://doi.org/10.1111/j.1528-1157.1988.tb03767.x

PMid:3409845

15. Kwan P, Brodie MJ. Early identification of refractory epilepsy. N Eng J Med. 2000; 342: 314 - 319.

https://doi.org/10.1056/NEJM200002033420503

PMid:10660394

16. Malik MA, Hamid MH, Ahmed TM, Ali Q. Predictors of intractable childhood epilepsy. Journal of the College of Physicians and Surgeons Pakistan. 2008;18(3):158-162.

17. Das CP, Sawhney IMS, Lal V, Prabhakar S. Risk of recurrence of seizures following single unprovoked idiopathic seizure. Neurol India. 2000; 48: 357-360.

18. Ohtsuka Y, Yoshinaga H, Kobayashi K, Murakimi N, Yamatogi Y, Oka E, et al. Predictors and underlying causes of medically intractable localized related epilepsy in childhood. Pediatric neurology. 2001; 27:181- 191.

19. Laroia N, Guillet R, Burchfiel J, Mc Bride, MC. EEG background as Predictor of Electrographic Seizures in High Risk Neonates. Epilepsia. 2006; 39(5): 545-551.

https://doi.org/10.1111/j.1528-1157.1998.tb01418.x

PMid:9596208

20. Shinnar S, Berg AT, Moshe SL, O'Dell C, Alemany $\mathrm{M}$, Newstein $\mathrm{D}$, et al. The risk of seizure recurrence after a first unprovoked afebrile seizure in childhood: an extended follow-up. Pediatrics. 1996; 98: 216-225.

21. Boyd SG, Harden A. Clinical neurophysiology of the central nervous system. In: Brett EM, editor. Paediatric Neurology. 3rd ed. New York: Churchill Livingstone;1997: 747-821. 